NOAA

National Marine

Fisheries Service
Fishery Bulletin

2 established 1881 ๙
Spencer F. Baird

First U.S. Commissione of Fisheries and founder of Fishery Bulletin
Abstract-Survey selectivity can be viewed as a function of the availability of the stock to the sampling gear and the sampling efficiency of the gear. A dome-shaped survey selectivity function is one in which survey selectivity decreases with larger and older fish. Such a function is estimated for eastern Bering Sea (EBS) Pacific cod (Gadus macrocephalus) in the NOAA National Marine Fisheries Service stock assessment model, which would be appropriate if large ( $\geq 55 \mathrm{~cm}$ in fork length) Pacific cod avoid capture by the EBS survey bottom trawl. To test this assumption, a field study was conducted to determine whether large Pacific cod escape capture by either outswimming the survey trawl or by swimming above the trawl. Our results show that large Pacific cod do not outswim the trawl because catches did not increase when we increased towing speed. Additionally, large Pacific cod do not routinely swim above the trawl because analysis of acoustic backscatter collected concurrently with trawl hauls indicated that only $4 \%$ of the acoustic backscatter attributed to Pacific cod occurred at heights above the headrope. We found no evidence that survey-gear efficiency decreased with increasing fish length either because large fish outswam the trawl or because they tend to occur further from the bottom. Therefore the results of our experiment do not support the use of a dome-shaped survey selectivity function in the EBS Pacific cod assessment model.

Manuscript submitted 16 June 2015. Manuscript accepted 20 May 2016.

Fish. Bull. 114:360-369 (2016).

Online publication date: 14 June 2016. doi: 10.7755/FB.114.3.8.

The views and opinions expressed or implied in this article are those of the author (or authors) and do not necessarily reflect the position of the National Marine Fisheries Service, NOAA.

\title{
Is the survey selectivity curve for Pacific cod (Gadus macrocephalus) dome-shaped? Direct evidence from trawl studies
}

\author{
Kenneth L. Weinberg ${ }^{1}$ \\ Cynthia Yeung (contact author) ${ }^{1}$ \\ David A. Somerton ${ }^{1}$ \\ Grant G. Thompson ${ }^{2}$ \\ Patrick H. Ressler ${ }^{1}$ \\ Email address for contact author: cynthia.yeung@noaa.gov \\ 1 Resource Assessment and Conservation Engineering Division \\ Alaska Fisheries Science Center \\ National Marine Fisheries Service, NOAA \\ 7600 Sand Point Way NE \\ Seattle, Washington 98115 \\ 2 Resource Ecology and Fisheries Management Division \\ Alaska Fisheries Science Center \\ National Marine Fisheries Service, NOAA \\ 7600 Sand Point Way NE \\ Seattle, Washington 98115
}

Fisheries stock assessment surveys are intended to produce an index of relative stock abundance that varies over time in constant proportion to the true stock abundance. In stock assessment models, the scaler that relates modeled abundance to a survey index is often considered a product of a constant catchability and of a fish age- or length-dependent survey selectivity function (which, hereafter, for reasons of simplicity, we refer to as length-dependent functions, but the same concept applies to agedependent functions). Both catchability and selectivity are typically estimated when a stock assessment model is fitted to data (Maunder and Piner, 2015), although, in some cases, the catchability coefficient is fixed a priori (Thompson ${ }^{1,2,3}$ ). The selectiv-

1 Thompson, G. G. 2013. Assessment of the Pacific cod stock in the eastern Bering Sea. In Stock assessment and fishery evaluation report for the groundfish ity of a survey can be viewed as a function of the availability of the various biological components of the fish stock to the sampling gear and of the sampling efficiency of the gear (i.e., the proportion of encountered animals that are captured; Maunder et al., 2014). However, the relative

resources of the Bering Sea/Aleutian Islands regions, p. 239-380. North Pacific Fishery Management Council, Anchorage, AK. [Available at website.]

2 Thompson, G. G. 2014. Assessment of the Pacific cod stock in the eastern Bering Sea. In Stock assessment and fishery evaluation report for the groundfish resources of the Bering Sea/Aleutian Islands regions, p. 255-436. North $\mathrm{Pa}$ cific Fishery Management Council, Anchorage, AK. [Available at website.]

3 Thompson, G. G. 2015. Assessment of the Pacific cod stock in the eastern Bering Sea. In Stock assessment and fishery evaluation report for the groundfish resources of the Bering Sea/Aleutian Islands regions, p. 251-470. North Pacific Fishery Management Council, Anchorage, AK. [Available at website.] 


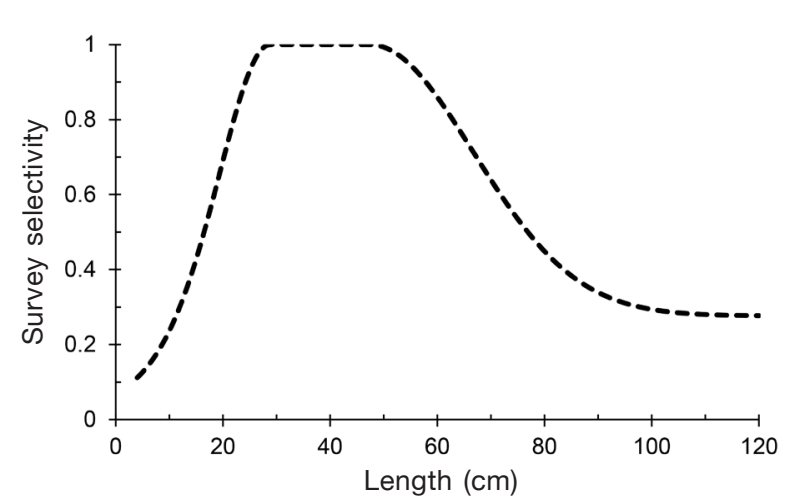

Figure 1

Length-based survey selectivity curve derived from the stock assessment of Pacific cod (Gadus macrocephalus) for the Bering Sea region in 2013. Lengths are given in fork lengths.

importance of availability (e.g., Do small fish occur at depths shallower than those of surveys?) and sampling efficiency (e.g., Do small fish pass through trawl mesh?) in determining the shape of a selectivity function is difficult to determine without additional information.

The shape of the survey selectivity function is at issue for the model used for stock assessment of Pacific cod (Gadus macrocephalus; Thompson ${ }^{1,2,3}$ ) in the eastern Bering Sea (EBS). The assessment model, conducted with the Stock Synthesis package, vers. 3.24q (Methot and Wetzel, 2013), is fitted to commercial catch data dating back to 1977, as well as to fisheriesindependent data from the National Marine Fisheries Service annual bottom trawl survey of demersal fishes in the EBS (hereafter referred to as the survey). The survey provides estimates of relative abundance and length compositions dating back to 1982 and age compositions from 1994 onward (Lauth and Nichol, 2013).

The current assessment model accepted by the NOAA National Marine Fisheries Service for fishery management, in addition to several historical model configurations, includes a flexible survey selectivity function that, after being fitted to the data, decreases at larger ( $\geq 55 \mathrm{~cm}$ in fork length [FL]) fish sizes (Thompson $1,2,3$; Fig. 1). This dome-shaped functional form has rising and descending limbs to either side of the top. The descending limb on the right side suggests that larger fishes are less vulnerable to the survey in some way, perhaps because they are better able to escape the trawl or are separated spatially from smaller fishes. In contrast, the more traditional asymptotic, survey selectivity function implies that the survey is sampling a greater proportion of the large fishes in the population. If an assessment model is not well informed by the data, there will be uncertainty about whether the shape of the estimated function accurately reflects the survey sampling processes or whether it reflects parameter confounding in the model (Maunder and Punt,
2013). The difference between interpretations of the shape of the estimated function with regard to these 2 types of uncertainty may have a pronounced effect on the determination of stock size and recommended harvest rates.

Field studies designed to describe survey-gear efficiency and stock availability provide a source of "direct" evidence and can be useful in the fitting of the selectivity function (Cadrin et al., 1999; Weinberg et al., 2004; Clark and Kaimmer, 2006; Nichol et al., 2007; Somerton et al., 2007; Somerton et al., 2013). We present the results from a new study and review results from previous works to determine whether direct evidence from field studies corroborates the dome-shaped survey selectivity function estimated by the current assessment model used for Pacific cod. Although we focus on Pacific cod, the concept that field experiments can better inform assessment models is applicable worldwide for multiple species.

If it is assumed that the survey covers the entire geographic range of Pacific cod in the EBS, a domeshaped selectivity function could result from a progressive decrease in trawl sampling efficiency for larger fish sizes. Sampling efficiency is dictated by 3 processes: vertical herding, horizontal herding, and escapement, all of which are dependent on trawl design, fishing procedures, fish behavior, and swimming endurance. Together, these processes play an important role in estimates of abundance and size composition of groundfish resources (Godø and Walsh, 1992).

Although studies on the behavior of Pacific cod are scarce, evidence has been collected from various field and laboratory experiments on other cold-water gadids and various demersal species, clearly showing that fish swimming stamina and reactions to trawling are species specific (He and Wardle, 1988; Winger et al., 1999), size dependent (Main and Sangster, 1981; He and Wardle, 1988; Winger et al., 1999), temperature affected (He, 1991; Winger et al., 1999), light responsive (Glass and Wardle, 1989; Walsh, 1991), and often density dependent (Godø et al., 1999; Kotwicki et al., 2014). Not all studies have come to the same conclusions for all species, or even within the same species in all cases, but the most universal observation is the inverse relationship between swimming speed and endurance. The faster a fish swims, the more energy required and the less time it is capable of sustaining such speed. If, however, a fish is able to swim fast enough and long enough to outpace a survey trawl, sampling efficiency will be reduced. Likewise, if large Pacific cod, more so than smaller Pacific cod, have the strength and stamina to outswim the survey trawl, survey selectivity will be reduced for the larger animals.

In addition to the possibility that larger Pacific cod avoid capture by outswimming the trawl, it is also possible that larger Pacific cod occur higher in the water column and are more likely to swim over the headrope of the survey trawl. The presence of fish in the water column can be documented by using acoustic data collected at the time of trawling. Analysis of acoustic 
data to estimate abundance has not been attempted for Pacific cod because of concerns stemming from the confounding of backscatter signals close to the seabed (i.e., separating the weaker fish signal from the stronger seabed signal), in the area known as the acoustic dead zone (Ona and Mitson, 1996), and from the difficulty of separating species-specific backscatter when multiple species with swim bladders, such as Pacific cod and walleye pollock (Gadus chalcogrammus), co-occur.

Our objective was to report the results of an experiment aimed at examining whether survey trawl efficiency decreases for large-size Pacific cod because they outswim the trawl or because they pass over its headrope. If such size-specific trawl efficiency can be demonstrated, it would support the application of a dome-shaped function in the stock assessment model for Pacific cod.

\section{Materials and methods}

\section{Experimental design}

Our experiment was designed to test the hypothesis that a substantial proportion of large Pacific cod avoid capture by outswimming the survey trawl under standard survey protocols (Stauffer, 2004). Secondarily, we were also able to provide a test of the hypothesis that a substantial proportion of Pacific cod are unavailable to the trawl because they are in the water column above the headrope of the survey trawl. A Pacific cod was considered large if its $\mathrm{FL}$ was $\geq 55 \mathrm{~cm}$, a definition based on lengths at the right tail of the selectivity schedule estimated in the 2013 stock assessment of EBS Pacific cod (Thompson ${ }^{1}$ ), for which estimated survey selectivity was less than 100.0 percent (Table 1, Fig. 1).

The experiment took the form of paired parallel tows: one vessel trawled at the survey standard speed of $1.5 \mathrm{~m} / \mathrm{s}(3 \mathrm{kn}$, slow), while the other vessel towed at a faster speed of $2.1 \mathrm{~m} / \mathrm{s}(4.0 \mathrm{kn}$, fast). Various Bering Sea fishermen of Pacific cod have reported tow speeds that range from 1.25 to $2.25 \mathrm{~m} / \mathrm{s}(2.5-4.5 \mathrm{kn})$, depending on vessel power, mesh size, and other trawl design features (senior author, personal commun.). We felt the upper limit for towing the survey trawl should be no more than $2.1 \mathrm{~m} / \mathrm{s}$ in order to maintain proper fishing configuration (Weinberg, 2003). At such a speed, we were $0.15 \mathrm{~m} / \mathrm{s}$ short of the fastest speeds for commercial trawling. If the number of large Pacific cod captured in the standard slow tows is no different from the number caught in the faster tows, we would conclude that Pacific cod did not outswim the survey trawl.

\section{Field operations}

The experiment was conducted during 3-5 August immediately following the 2013 NOAA EBS bottom trawl survey aboard the 2 trawlers used for the survey. An 83-112 eastern trawl (standard for the EBS survey) was used in this experiment. The 83-112 eastern trawl

\section{Table 1}

Survey selectivity (rounded to one decimal place) by length group based on the length-based schedule of the 2013 assessment model used for Pacific cod (Gadus macrocephalus) in the eastern Bering Sea. Ranges for length groups are provided in fork lengths (FLs).

\begin{tabular}{cc}
\hline Survey selectivity & Length group (cm FL) \\
\hline 1.0 & $34-54$ \\
0.9 & $55-60$ \\
0.8 & $61-65$ \\
0.7 & $66-69$ \\
0.6 & $70-74$ \\
0.5 & $75-79$ \\
0.4 & $80-88$ \\
0.3 & $89-105$ \\
\hline
\end{tabular}

is a 2-seam flatfish trawl with a $25.3 \mathrm{~m}$ (83 ft) long headrope and a $34.1 \mathrm{~m}$ (112 ft) long footrope (more details are provided in Weinberg, 2003; Lauth and Nichol, 2013). The simple $5.2 \mathrm{~cm}$ diameter footrope is weighted with $75 \mathrm{~kg}$ of chain hung in equal loops along its length from which the nylon netting is attached. Mesh size varies from a maximum of $10.2 \mathrm{~cm}$ in the wings and throat to a minimum of $3.2 \mathrm{~cm}$ for the liner in the codend. Each side of the net is attached to a steel V-door $(1.8 \times 2.7 \mathrm{~m})$ that weighs approximately $816 \mathrm{~kg}$ by a pair of 54.9-m-long, 1.6-cm-diameter bare wire bridles. Because faster trawling has been shown to exacerbate inconsistencies in seabed contact of this trawl (Weinberg, 2003), an additional $34 \mathrm{~kg}$ of weight was secured to the footrope, then monitored with a bottom contact sensor for all tows in this experiment.

The major difference between tows of our experiment and standard survey tows was towing speed. All other trawling procedures followed those used during the survey (e.g., straight-line towing, locked winches with equal lengths of warp, standard warp length to depth ratios, and setting and retrieval methods designed to lower the net down on the seabed in fishing configuration quickly at the start of a tow and to raise it off the seabed quickly at the end of a tow). Our balanced-pair design called for repetitive parallel towing and vessels safely separated by no more than $463 \mathrm{~m}(0.25 \mathrm{nmi})$. On odd-numbered pairs, one vessel was randomly selected to tow at the standard survey speed of $1.5 \mathrm{~m} / \mathrm{s}$, while the other vessel towed at the faster speed of $2.1 \mathrm{~m} / \mathrm{s}$. On even-numbered pairs, the vessels switched towing speeds. To reduce potential bias from sea conditions, the faster boat was randomly appointed to fish either the port or starboard side of the slower boat.

When fishing with 2 boats at different speeds, we had a choice of enforcing either consistent tow duration (time) or consistent tow length (distance). Because it has been shown that variation in tow durations (15.0 
and $30.0 \mathrm{~min}$ ) did not affect the size distribution of catches for some Atlantic species, including Atlantic cod (Gadus morhua; Godø et al., 1990; Walsh ${ }^{4}$ ), we elected to reduce the duration of the faster tows so that the distance fished and swept area of tows were similar between the 2 speeds (Wileman et al., 1996). Hence, the duration of the slow $(1.5 \mathrm{~m} / \mathrm{s})$ and fast $(2.1 \mathrm{~m} / \mathrm{s})$ tows were set at 30.0 and $22.5 \mathrm{~min}$, respectively, measured from the time the nets were on bottom and the winches were locked to the time when trawl retrieval was initiated.

Towing occurred at 2 independent sites, one at a depth of $136 \mathrm{~m}$ and the other at a depth of $86 \mathrm{~m}$. Ten successful pairs of fast and slow tows were made at the deep site, and 14 pairs were completed successfully at the shallow site. All captured Pacific cod (sex not determined) were measured to the nearest centimeter (FL).

\section{Data analysis}

Swept area Swept area for each haul was estimated as the average net width from data collected with a Marport ${ }^{5}$ acoustic net mensuration system (Marport Stout Inc., Snohomish, WA), multiplied by the length of the tow path, derived from GPS data of vessel locations at first and last contact of the footrope with the seabed; seabed contact was determined with a bottom contact sensor (Somerton and Weinberg, 2001). Outlier measurements of net width were removed by using a sequential outlier rejection algorithm, and the remaining data were fitted with a smoothed spline from which the average net width was calculated for each tow (Kotwicki et al., 2011).

Measuring the swept area of each tow was complicated by instrument failure during some tows. Therefore, only a subset of all tows produced valid net width data. Paired $t$-tests were used to test for a difference in the swept area between the fast and the slow tows of each pair where net widths were available for both tows. If the difference was found not to be significant $(P>0.05)$ in this subset of tows after the data from our bottom contact sensors were examined thoroughly for anomalies that would indicate the likelihood of high variability in net width during a tow, we assumed the swept area was not different for any paired tows and used the raw catch (counts) from all tows as the dependent variable in subsequent analyses.

Effect of towing speed on catch The null hypothesis that the catch of large Pacific cod at a fast towing speed $\left(c_{\mathrm{f}}\right)$ was no different than the catch of large $\mathrm{Pa}$ cific cod at a slow towing speed $\left(c_{\mathrm{s}}\right)$ was tested by using paired-sample tests, against the one-sided alternative

\footnotetext{
${ }^{4}$ Walsh, S. J. 1991. Effect of tow duration on gear selectivity. NAFO SCR Doc. 91/84, 9 p. [Available at website.]

5 Mention of trade names or commercial companies is for identification purposes only and does not imply endorsement by the National Marine Fisheries Service, NOAA.
}

that $c_{\mathrm{f}}$ was greater than $c_{\mathrm{s}}$. First, the probability of either towing speed being equally likely to obtain greater catch was calculated with a sign test: the binomial probability that $\mathrm{c}_{\mathrm{f}}$ was greater than $\mathrm{c}_{\mathrm{s}}$ in $x$ pairs (successes) out of the total $y$ pairs of tows (trials) observed if the null hypothesis of no effect of speed on catch was true. A paired $t$-test was then conducted to further confirm the result of the less-sensitive, but more robust, sign test. The null hypothesis of the $t$-test was that there was no mean difference $(\bar{d})$ between $\ln \left(\mathrm{c}_{\mathrm{f}}\right)$ and $\ln \left(\mathrm{c}_{\mathrm{s}}\right)$ of the paired tows $\left(H_{0}: \bar{d}=0\right.$, i.e. the mean ratio $\overline{c_{\mathrm{f}} / c_{\mathrm{s}}}=1$ ), assuming that the differences between pairs were normally distributed. The power (1- $\beta$ ) of the $t$-test was calculated for a 1 -sided $\left(H_{\mathrm{a}}: \bar{d}>0\right)$ alternative hypothesis on the basis of the $t$-distribution, observed standard deviation (SD) of $\ln \left(c_{\mathrm{f}}\right)-\ln \left(c_{\mathrm{s}}\right)$, sample size $(n)$ of 24 pairs of tows, and significance level $(\alpha)$ of 0.05 . The power was calculated for a range of $\bar{d}$ for $H_{\mathrm{a}}$ from 0.1 to 1.0 , where $e^{\bar{d}}=c_{\mathrm{f}} / c_{\mathrm{s}}$.

Finally, we estimated $\bar{d}$ on the basis of the length-derived, double normal, survey selectivity schedule from the stock assessment model for Pacific cod in the EBS (see appendix A in Methot and Wetzel, 2013; Thompson $\left.^{1}\right)$. For our study, we assumed that at the fast towing speed, no large Pacific cod can escape the net and all available fish are caught and that at the slow towing speed, the large Pacific cod available can escape the net in the proportion indicated by the survey selectivity function. To increase our sample size, we pooled the numbers of fish caught in this experiment into length groups with the same survey selectivity, rounded to the first decimal place (Table 1). The total expected catch in a tow based on the curve $\left(c_{\mathrm{e}}\right)$ was calculated as the sum of the catch in each length group in the slow tow $\left(c_{\mathrm{s}-1}\right)$ divided by the survey selectivity for that length group $\left(\mathrm{s}_{1}\right): c_{\mathrm{e}}=\sum_{l=1}^{L} c_{\mathrm{s}-1} / s_{1}$. On the basis of the assumptions, $c_{\mathrm{e}}$ would be the expected catch in a fast tow. Therefore, the mean ratio of expected catch to the catch of the slow tow for the $n$ pairs of tows, $\frac{\sum_{i=1}^{n} c_{e-i} / c_{s-i}}{n}$, would be the expected mean ratio of catch in the fast tow over the slow tow.

Vertical distribution Simrad ES60 echosounders were used in both survey vessels (Kongsberg Maritime AS, Kongsberg, Norway) and operated at frequencies of 38 and $120 \mathrm{kHz}$ with a sampling rate of 1-2 pings/s to collect acoustic backscatter data. The sampling resolution of these data was approximately $0.2 \mathrm{~m}$ vertically and $0.8-2.1 \mathrm{~m}$ horizontally at ship speeds of 1.5 and $2.1 \mathrm{~m} / \mathrm{s}$ (at 3 and $4 \mathrm{kn}$ ). Given nominal beam widths of $7^{\circ}$ at both frequencies, depth of the hull-mounted transducers $(4 \mathrm{~m})$, and depth of the seafloor at the deep study site $(136 \mathrm{~m})$, the extent sampled by each ping was a circle with a diameter of approximately $16 \mathrm{~m}$ (close to the 18-m average net width for this depth) and an area of $205 \mathrm{~m}^{2}$. These data were analyzed with Echoview, vers. 5.4.90 (Echoview Software Pty. Ltd., Hobart, Australia), which afforded us the opportunity to detect whether Pacific cod occurred above our net opening at 


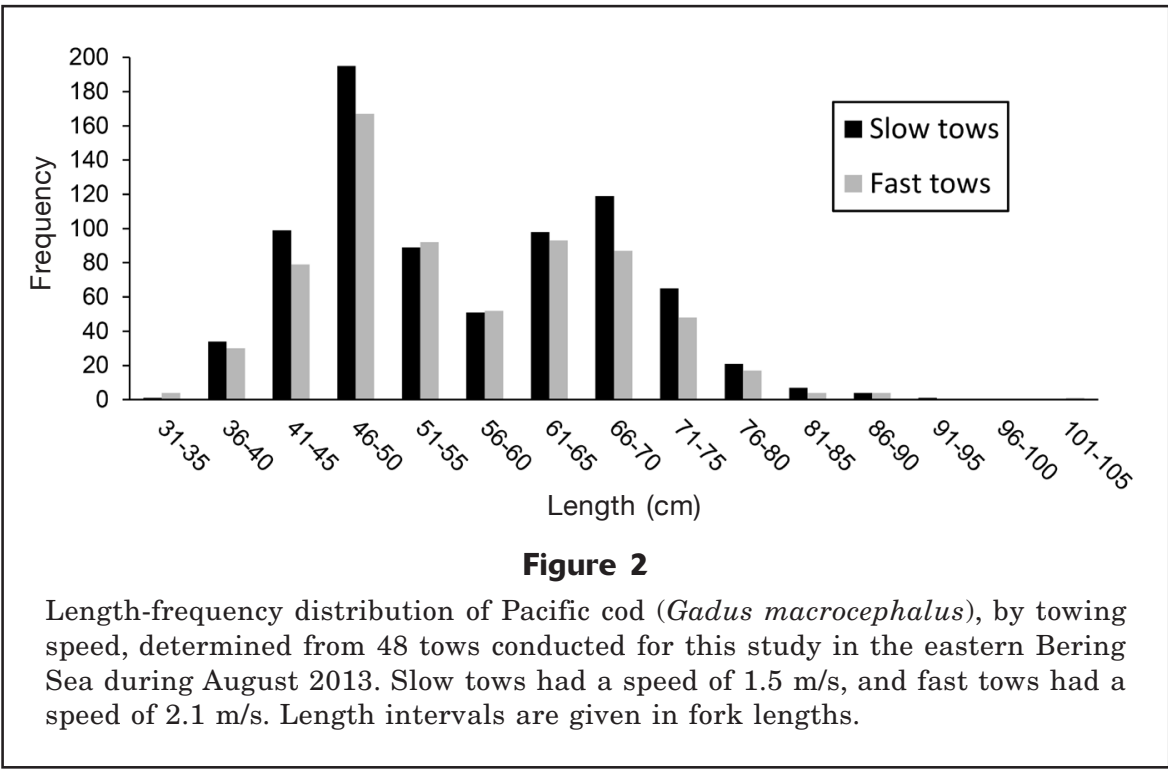

the moment they were sampled by the echosounder on the vessel.

The difference between frequencies (120 and 38 $\mathrm{kHz})$ in mean volume backscattering strength $\left(S_{\mathrm{v}}, \mathrm{dB}\right.$ re $1 / \mathrm{m}$; cf. MacLennan et al., 2002) was used to identify backscatter consistent with that of fishes with swim bladders. For analysis, backscatter data were grouped in bins, each of which had a resolution of 20 pings (horizontal) by $5 \mathrm{~m}$ (vertical). Bins for which the difference between $S_{\mathrm{v}}$ at $120 \mathrm{kHz}$ and $S_{\mathrm{v}}$ at $38 \mathrm{kHz}$ was between -10 and $8 \mathrm{~dB}$ were classified as backscatter that indicated fish (De Robertis et al., 2010). Only bins for which the backscatter had a signal-to-noise ratio of at least $10 \mathrm{~dB}$ (De Robertis and Higginbottom, 2007) were included in the analysis.

Fish backscatter per unit of area $\left(s_{\mathrm{A}}, \mathrm{m}^{2} / \mathrm{nmi}^{2}\right)$ was then integrated by using an $\mathrm{S}_{\mathrm{v}}$ integration threshold of $-70 \mathrm{~dB}$ in several depth layers referenced to a 0.25 $m$ backstep above the seabed echo (0.25-2.0, 2.0-2.5, 2.5-3.0, 3.0-7.0, and 7.0-16.0 m). The upper bound of the first depth interval matched the mean headrope height of this experiment. Similarly, a height of $2.5 \mathrm{~m}$ corresponds to a survey-wide average headrope height for the 83-112 eastern trawl used to assess Pacific cod in the EBS (Nichol et al., 2007), a height of $7.0 \mathrm{~m}$ corresponds to a survey-wide average headrope height for the poly-Noreastern trawl used by the NOAA Alaska Fisheries Science Center to assess Pacific cod in the Gulf of Alaska region (Nichol et al., 2007), and a height of $16.0 \mathrm{~m}$ corresponds to an estimated effective fishing height for the 83-112 eastern trawl that is used to assess walleye pollock in the EBS (Kotwicki et al., 2013) and that perhaps may apply to Pacific cod as well.

The results of this analysis of backscatter data were examined for evidence of fish above the headrope height (mean: $2.0 \mathrm{~m}$ ) during the time the demersal trawl was in contact with the seabed, after accounting for horizontal setback of the trawl behind the vessel (approximately 3-4 min depending on vessel speed). The acoustic assessment was restricted to the deep study site because catches there consisted almost exclusively of Pacific cod and flatfishes and, therefore, it was reasonable to assume that any backscatter that indicated fish with swim bladders was a result of the presence of Pacific cod. It was not possible to make such an assumption for data collected at the shallow study site because the catches there were dominated by walleye pollock, which cannot be acoustically distinguished from Pacific cod.

\section{Results}

\section{Summary of catches}

During the 48 experimental tows, 1462 Pacific cod, ranging in size from 34 to $105 \mathrm{~cm} \mathrm{FL,} \mathrm{were} \mathrm{caught,}$ but only 2 fish were larger than $90 \mathrm{~cm} \mathrm{FL} \mathrm{(Fig.} \mathrm{2).}$ Of the captured fish, 701 individuals were large $(\geq 55$ $\mathrm{cm}$ FL) and included in further analyses. The bottom temperatures during the experiment ranged between $2.6^{\circ} \mathrm{C}$ and $2.7^{\circ} \mathrm{C}$.

\section{Swept area}

Of the 24 paired tows, 16 pairs had reliable net mensuration data with which we could test differences in swept area by pair. The mean difference in swept area between paired tows (fast and slow) was -0.072 ha, a variance that was not significant $(t=-0.492, \mathrm{df}=15$, $P=0.63)$. The fast tows swept a greater area than that swept by the slow tows during half of the pairs ( 8 of 16 tows). Conversely, the slow tows swept a greater area than that swept by the fast tows during the other half of pairs. Bottom contact sensors provided reliable data 


\section{Table 2}

Catch of large ( $\geq 55 \mathrm{~cm}$ in fork length) Pacific cod (Gadus macrocephalus) at fast $\left(c_{\mathrm{f}}\right)$ and slow $\left(c_{\mathrm{s}}\right)$ towing speeds for each pair of tows conducted for this study in the eastern Bering Sea in August 2013. Pairs 1-10 were deep tows. Pairs 11-24 were shallow tows. The expected catch $\left(c_{\mathrm{e}}\right)$ was calculated on the basis of the length-based selectivity curve from the 2013 National Marine Fisheries Service stock assessment as described in the Materials and methods section.

\begin{tabular}{rrrrrr}
\hline Tow pair & $c_{\mathrm{f}}$ & $c_{\mathrm{s}}$ & $c_{\mathrm{f}} / c_{\mathrm{s}}$ & $c_{\mathrm{e}}$ & $c_{\mathrm{e}} / c_{\mathrm{s}}$ \\
\hline 1 & 17 & 22 & 0.8 & 33 & 1.5 \\
2 & 16 & 6 & 2.7 & 8 & 1.4 \\
3 & 14 & 10 & 1.4 & 19 & 1.9 \\
4 & 11 & 15 & 0.7 & 26 & 1.8 \\
5 & 5 & 12 & 0.4 & 18 & 1.5 \\
6 & 7 & 26 & 0.3 & 42 & 1.6 \\
7 & 5 & 5 & 1.0 & 8 & 1.5 \\
8 & 7 & 9 & 0.8 & 15 & 1.7 \\
9 & 9 & 9 & 1.0 & 15 & 1.6 \\
10 & 15 & 13 & 1.2 & 19 & 1.5 \\
11 & 14 & 14 & 1.0 & 20 & 1.4 \\
12 & 19 & 42 & 0.5 & 57 & 1.4 \\
13 & 22 & 10 & 2.2 & 14 & 1.4 \\
14 & 17 & 15 & 1.1 & 19 & 1.3 \\
15 & 17 & 16 & 1.1 & 22 & 1.4 \\
16 & 22 & 36 & 0.6 & 50 & 1.4 \\
17 & 11 & 27 & 0.4 & 38 & 1.4 \\
18 & 22 & 19 & 1.2 & 31 & 1.6 \\
19 & 16 & 23 & 0.7 & 32 & 1.4 \\
20 & 16 & 15 & 1.1 & 20 & 1.4 \\
21 & 15 & 8 & 1.9 & 13 & 1.6 \\
22 & 7 & 7 & 1.0 & 10 & 1.5 \\
23 & 6 & 7 & 0.9 & 9 & 1.3 \\
24 & 16 & 9 & 1.8 & 13 & 1.4 \\
& & & & & \\
& & & & &
\end{tabular}

on all tows, indicating that trawl footropes were firmly in contact with the substrate and providing evidence for our decision to use all 24 pairs of data in subsequent analyses.

\section{Effect of towing speed on catches}

Fast tows had larger catches of large Pacific cod in only 10 of 24 paired tows. In those 10 pairs, the catches from fast tows were 1.1 to 2.7 times (mean: 1.6 times) greater than the catches from slow tows (Table 2). A sign test indicated that larger catches were not significantly more frequent in fast tows (successes $=10$, trials $=24, P=0.924)$; larger catches in at least 18 of the 24 pairs would be required for significance $(P \leq 0.05)$.

The mean difference $\bar{d}$ between $\ln \left(c_{\mathrm{f}}\right)$ and $\ln \left(c_{\mathrm{s}}\right)$ of -0.08 (SD 0.55) was approximately normally distributed according to a $\chi^{2}$ goodness-of-fit test $\left(\chi^{2}{ }_{5-2-1}=1.226\right.$, $P=0.54$; Fig. 3). The mean of $c_{\mathrm{f}} / c_{\mathrm{s}}$ was 1.1 (SD 0.58) (range: $0.3-2.7$; Table 2). A paired $t$-test indicated that the difference in $\ln ($ catch $)$ between fast and slow tows was not statistically significant $\left(t_{23}=-0.69, P=0.50\right)$. The expected mean ratio of the catch of large Pacific cod in fast tows over slow tows $\left(c_{\mathrm{f}} / c_{\mathrm{s}}\right)$ was 1.5 (range: $\left.1.3-1.9\right)$. If the expected ratio of 1.5 were true, then the power of a 1 -sided $t$-test $\left(H_{\mathrm{a}}: \bar{d}>0\right)$ would be $97 \%$ in rejecting $H_{0}$ (Table 3).

\section{Vertical distribution}

Demersal fish backscatter was fairly low, as would be expected given the low numbers of Pacific cod captured. The strongest demersal fish backscatter $\left(S_{\mathrm{v}} \sim-45 \mathrm{~dB}\right)$ appeared very close to the acoustically detected seabed; fish backscatter farther off the seabed was generally weaker in comparison $\left(S_{\mathrm{v}} \sim-65 \mathrm{~dB}\right)$. The demersal fish backscatter observed below the average headrope height of $2.0 \mathrm{~m}$ during this study was a very large fraction of fish backscatter integrated over all depth layers examined (median proportion: 0.96; Fig. 4). In an absolute sense, the highest demersal fish backscatter values were found within the depth layer of $0.25-2.0 \mathrm{~m}$ (Fig. 5); the median fish $s_{\mathrm{A}}$ in this layer was more than 14 times that in any other depth layer.

\section{Discussion}

We failed to detect a difference between slow $(1.5 \mathrm{~m} / \mathrm{s})$ and fast $(2.1 \mathrm{~m} / \mathrm{s})$ towing speeds in the rates at which 


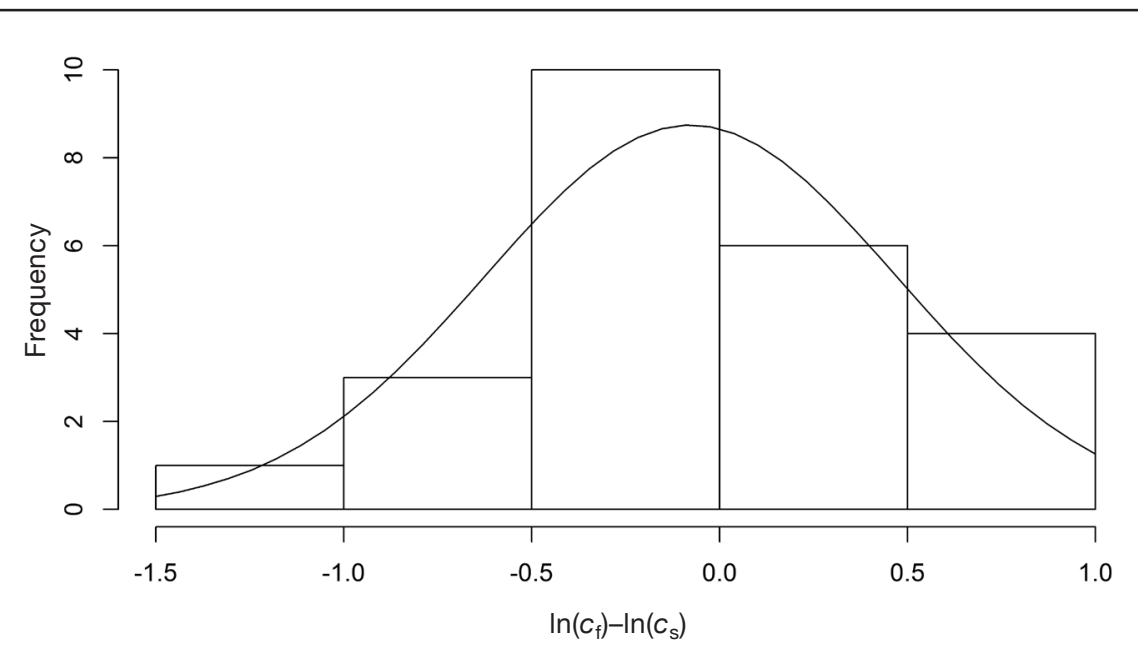

Figure 3

Normal distribution curve fitted to a histogram of the differences in $\ln ($ catch) of large Pacific cod (Gadus macrocephalus) between fast and slow towing speeds (goodness-of-fit: $\chi^{2}{ }_{5-2-1}=1.226, P=0.54$ ) from this study conducted in 2013 in the eastern Bering Sea. $\ln \left(c_{\mathrm{f}}\right)=$ catch at the fast towing speed of $2.1 \mathrm{~m} / \mathrm{s} ; \ln \left(c_{\mathrm{s}}\right)=$ catch at the slow towing speed of $1.5 \mathrm{~m} / \mathrm{s}$.

\section{Table 3}

Power of $t$-test (probability of rejecting $\mathrm{H}_{0}$ when it is false) for the mean difference $\bar{d}$ between $\ln \left(c_{\mathrm{f}}\right)\left(c_{\mathrm{f}}=\right.$ catch of fast tows $)$ and $\ln \left(c_{\mathrm{s}}\right)\left(c_{\mathrm{s}}=\right.$ catch of slow tows), where $H_{0}: \bar{d}=0$, against one-sided $H_{\mathrm{a}}: \bar{d}>0$ alternative hypothesis. The $t$-distribution was used with a degree of freedom of 23 and a significance level $(\alpha)$ of 0.05 .

\begin{tabular}{ccc}
\hline $\bar{d}$ & $e^{\bar{d}}=c_{\mathrm{f}} / c_{\mathrm{s}}$ & Power \\
\hline 0.1 & 1.1 & 0.21 \\
0.2 & 1.2 & 0.53 \\
0.3 & 1.3 & 0.83 \\
0.4 & 1.5 & 0.97 \\
0.5 & 1.6 & 0.99 \\
1.0 & 2.7 & 1.00 \\
\hline
\end{tabular}

large Pacific cod ( $\geq 55 \mathrm{~cm}$ FL) were caught with the 83-112 eastern trawl. Therefore, we surmise that if the dome-shaped selectivity estimated in recent stock assessments (Thompson ${ }^{1,2,3}$ ) is due to a decrease in trawl efficiency for large Pacific cod, that decrease is not attributable to fish outswimming the net. We are unaware of other direct studies on the swimming behavior of Pacific cod in relation to trawling activity. Consequently, to make inferences, we must draw upon the conclusions from research conducted on other, similar species.

Of the many species studied for their swimming capabilities, the Atlantic cod is most close-

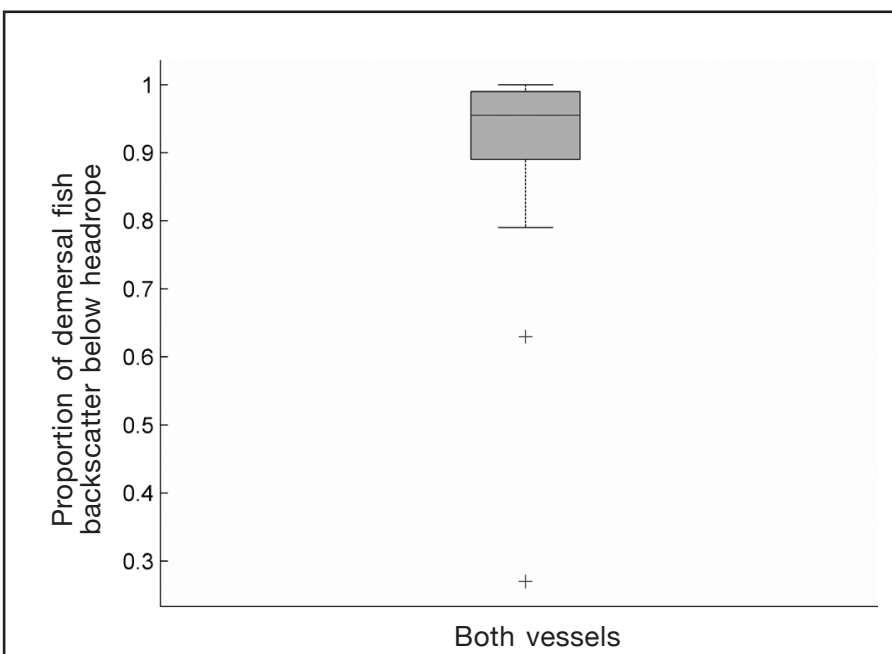

Figure 4

Boxplot indicating the proportion of demersal fish backscatter, in all depth layers examined $(0.25-16.0 \mathrm{~m}$ above the sounder-detected bottom echo), found below the average headrope height but above the $0.25-\mathrm{m}$ dead zone $(0.25-2.0 \mathrm{~m}$; $n=20$ tows), for this study conducted in August 2013 in the eastern Bering Sea. The line within the shaded box indicates the median value, the shaded box indicates the first and third quartiles, the horizontal lines outside the shaded box indicate a distance of 1.5 times the interquartile range above the third quartile and below the first quartile, and the plus marks indicate outliers outside these lines.

ly related to Pacific cod. Winger et al. (2000) performed a comprehensive tank study on the swimming stamina of At- 
lantic cod and deduced that changes in towing speed would affect the catching efficiency of this species. In their study, Atlantic cod were subjected to water velocities that were slower than our towing speeds, but water temperatures were close to those in our study $\left(2.6^{\circ} \mathrm{C}\right)$. At the towing speeds used by fishermen in the northeast Atlantic $(1.0 \mathrm{~m} / \mathrm{s})$, Atlantic cod were able to maintain sustained swimming speeds for $10 \mathrm{~min}$, but at a speed of $1.5 \mathrm{~m} / \mathrm{s}$ (the slow towing speed in our study), they could maintain swimming speed for only $1 \mathrm{~min}$. If Pacific cod swimming abilities are indeed similar to those of Atlantic cod, then, given the towing speeds of $1.5 \mathrm{~m} / \mathrm{s}$ or greater used in our experiment, we expect that Pacific cod maximum sustained swimming speeds would not be enough to elude capture even during a haul lasting $22.5 \mathrm{~min}$, the shorter tow duration used in our experiment.

Large Pacific cod do not escape capture by outswimming the survey trawl, as indicated by our study results: catches when towing at the fast speed were no different than catches when towing at the slow speed. This result indicates that, once Pacific cod reach the trawl mouth, they lack the means to swim fast enough or long enough to escape forward around the wing ends. In situ video evidence shows that this species tends to hold station in front of the footrope for only brief periods before slipping back into the net $\left(\operatorname{Rose}^{6}\right)$. Large Pacific cod are unlikely to swim over the net because acoustic backscatter indicates that most Pacific cod, when in the presence of a trawler, occur very close to the bottom within the vertical fishing dimensions of the trawl. In addition, findings from previous studies on gadid behavior indicate that trawl gear elicits a diving response in fish, not a rising response. The remaining avenues for escapement that could explain lowered trawl efficiency are 1) large Pacific cod could swim through the small mesh of the survey net, an option that is physically impossible and 2) they could escape beneath the footrope, the frequency of which has been previously shown to be negligible (Weinberg et al., 2002).

If large Pacific cod are not outswimming the trawl, perhaps they are swimming over the headrope-a notion that would also explain a drop in selectivity for large fish related to both trawl sampling efficiency and availability. Here, we used fish backscatter to within $0.25 \mathrm{~m}$ of the seabed to assess the vertical distribution of Pacific cod near the seafloor during our experiment. This process discards potential backscatter from fish in the acoustic dead zone (Ona and Mitson, 1996), which is located very close to the seabed and could be an area of concern for an absolute estimate of all fish $s_{\mathrm{A}}$. However, the distribution of fishes within the dead zone is less important for our main interest of detect-

${ }^{6}$ Rose, C. R. 2010. Unpubl. data. Resour. Assess. Conserv. Eng. Div., Alaska Fish. Sci. Cent., NOAA, Seattle, WA 98115.

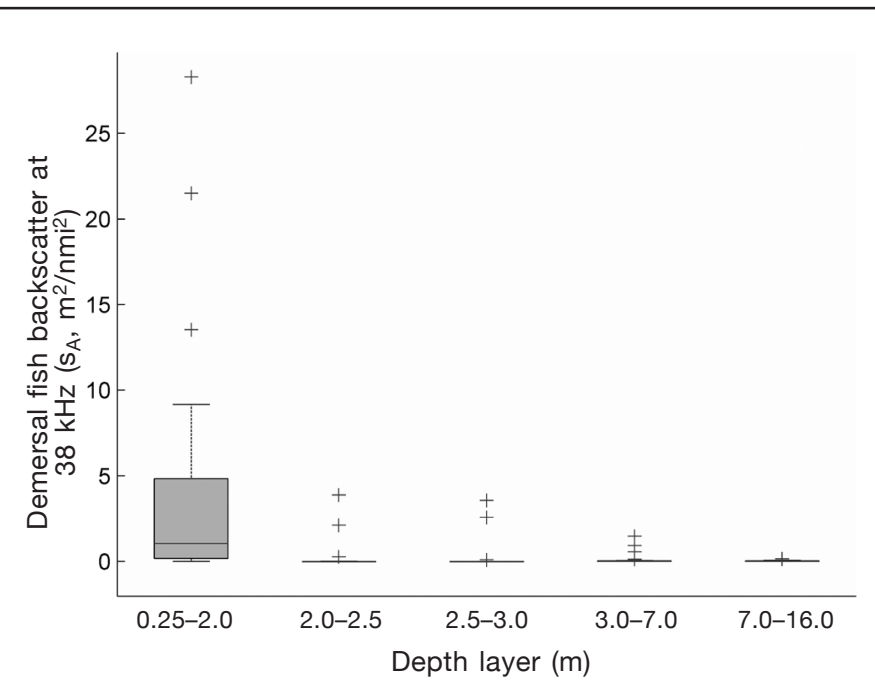

Figure 5

Boxplots of demersal fish backscatter per unit of area $\left(s_{\mathrm{A}}\right)$ at 5 depth layers within $16 \mathrm{~m}$ of the sounder-detected bottom ( $n=20$ tows), determined from acoustic data collected at a frequency of $38 \mathrm{kHz}$ in August 2013 in the eastern Bering Sea. The horizontal line across the shaded box indicates the median value, the shaded box indicates the first and third quartiles, the lines outside the shaded box indicate a distance of 1.5 times the interquartile range above the third quartile and below the first quartile, and the plus marks indicate outliers outside these lines.

ing Pacific cod occurrence in relation to the headrope height of the trawl; indeed, if most Pacific cod are in the acoustic dead zone, they clearly are not above the headrope height during vessel passage.

Analysis of acoustic backscatter collected during towing indicated that only $4 \%$ of the total backscatter attributed to Pacific cod occurred above the height of the survey headrope, although the backscatter was measured at the vessel rather than at the net itself, meaning that any upward movement of fish after vessel passage would be undetected. Again, there are no previous studies on the vertical swimming behavior of Pacific cod in relation to trawls from which we can draw inferences. Studies of walleye pollock (Kotwicki et al., 2013) and Atlantic cod show that these 2 commercially important gadids were stimulated to dive, rather than rise; their response to trawl warps may be both acoustically, as well as visually, driven according to Handegard and Tjøstheim (2005). This behavior is also acknowledged by commercial fishermen who tend to drag their nets below semipelagic schools. There is, therefore, little reason to believe that Pacific cod swam over the headrope during this experiment.

Nichol et al. (2007) did, however, on the basis of 11 archival tags, provide evidence of an off-bottom portion of the Pacific cod vertical distribution during daylight hours (the time during which the EBS survey is conducted) when the fish were in an undisturbed state 
(i.e., tags were deployed in the absence of vessel noise or oncoming trawl gear). They postulated that large Pacific cod swim above the survey-wide average height of the headrope $(2.5 \mathrm{~m})$ approximately $53 \%$ of the time and within $10 \mathrm{~m}$ of the seabed $95 \%$ of the time. Although their study was based on an interpretation of estimated tidal activity, their work has had a pronounced impact on the current stock assessment model, such that the catchability coefficient was fixed so that the average product of catchability and selectivity size range (60-81 cm FL) equaled 47\% (Thompson ${ }^{1,2,3}$ ).

We agree with Nichol et al. (2007), in that it seems unlikely for the survey trawl to catch $100 \%$ of the Pacific cod in its path $100 \%$ of the time; however, we cast doubt on the conclusion that more than $50 \%$ of large fish swim above the trawl in the presence of trawling activity. Nichol et al.'s study was based on a very small sample, and one could argue that our study similarly lacked broad geographical range, over areas with varying habitat complexity, light intensity, and temperatures that (although never shown) may all have an effect on Pacific cod vertical distributions or perhaps even swimming speeds (Ferno et al., 2011). Additional experiments focusing on these factors would shed additional light on the matter.

Survey selectivity functions in stock assessment models are designed to be a parsimonious representation of the relative size dependency of the survey sampling process. However, stock assessment models can be quite complex, often including hundreds of parameters that must be estimated when the models are fitted to data (Maunder and Punt, 2013; Methot and Wetzel, 2013), and such complexity can lead to parameter correlation and confounding during model fitting. One example of this confounding is the correlation between survey selectivity parameters and the natural mortality rate (Thompson, 1994), a relationship that can lead to ambiguity in ascribing unexpectedly low catches at a particular fish length to either reduced survey selectivity or to an underestimated natural mortality rate.

We are, therefore, unable to corroborate the dome shape for the selectivity function of the survey of Pacific cod in the EBS by using direct evidence from this and other field studies in which trawl sampling efficiency has been examined. If the estimated survey selectivity function determined from the model is indeed correct, then the mechanisms that explain the steep descent of the right-hand tail must consist of something other than sampling efficiency. Four possible explanations for this steep descent of the right-hand tail are that 1) large fish migrate out of the survey grid, hence becoming unavailable to the survey; 2) sampling effort in preferred habitat of large fish embedded within the EBS survey area is not sufficient; 3) large fish prefer the small areas of rough, untrawlable bottom embedded within the EBS survey area; and 4) the relationships between availability and efficiency, on the one hand, and between catchability and selectivity, on the other, are complicated enough that studies of availability or efficiency alone are insufficient to explain catch- ability or selectivity (see Suppl. Text). If something is misspecified in the assessment model (e.g., perhaps the natural mortality rate is too low or varies with fish size), the selectivity of the survey for large Pacific cod would be closer to unity and could lead to a change in the harvest quotas. Therefore, further research on these subjects is needed to clarify the mechanisms responsible for the selectivity of the survey.

\section{Acknowledgments}

Funding for this project was provided by the National Marine Fisheries Service, National Cooperative Research Program with Industry. We are grateful for the advice provided by A. De Robertis on echo-integration techniques and for the helpful comments from our reviewers D. Nichol and S. Kotwicki. In addition, we thank our anonymous reviewers who sacrificed their valuable time to contribute to the advancement of fisheries science.

\section{Literature cited}

Cadrin, S. X., S. H. Clark, D. F. Schick, M. P. Armstrong, D. McCarron, and B. Smith.

1999. Application of catch-survey models to the northern shrimp fishery in the Gulf of Maine. N. Am. J. Fish. Manage. 19:551-568. Article

Clark, W. G., and S. M. Kaimmer.

2006. Estimates of commercial longline selectivity for Pacific halibut (Hippoglossus stenolepis) from multiple marking experiments. Fish. Bull. 104:465-467.

De Robertis, A., and I. Higginbottom.

2007. A post-processing technique to estimate the signal-to-noise ratio and remove echosounder background noise. ICES J. Mar. Sci. 64:1282-1291. Article

De Robertis, A., D. R. McKelvey, and P. H. Ressler.

2010. Development and application of empirical multifrequency methods for backscatter classification in the North Pacific. Can. J. Fish. Aquat. Sci. 67:1459-1474. Article

Ferno, A., T. Jørgensen, S. Løkkeborg, and P. D. Winger.

2011. Variable swimming speeds in individual Atlantic cod (Gadus Morhua L.) determined by high-resolution acoustic tracking. Mar. Biol. Res. 7:310-313. Article

Glass, C. W., and C. S. Wardle.

1989. Comparison of the reactions of fish to trawl gear, at high and low light intensities. Fish. Res. 7:249-266. Article

Godø, O. R., and S. J. Walsh.

1992. Escapement of fish during bottom trawl sampling-implications for resource assessment. Fish. Res. 13:281-292. Article

Godø, O. R., M. Pennington, and J. H. Vølstad.

1990. Effect of tow duration on length composition of trawl catches. Fish. Res. 9:165-179. Article

Godø, O. R., S. J. Walsh, and A. Engås.

1999. Investigating density-dependent catchability in bottom-trawl surveys. ICES J. Mar. Sci. 56:292-298. Article 
Handegard, N. O., and D. Tjøstheim.

2005. When fish meet a trawling vessel: examining the behaviour of gadoids using a free-floating buoy and acoustic split-beam tracking. Can. J. Fish. Aquat. Sci. 62:2409-2422. Article

He, $\mathrm{P}$.

1991. Swimming endurance of the Atlantic cod, Gadus morhua L., at low temperatures. Fish. Res. 12:65-73. Article

He, P., and C. S. Wardle.

1988. Endurance at intermediate swimming speeds of Atlantic mackerel, Scomber scombrus L., herring, Clupea harangus L., and saithe, Pollachius virens L. J. Fish. Biol. 33:255-266. Article

Kotwicki, S., M. H. Martin, and E. A. Laman.

2011. Improving area swept estimates from bottom trawl surveys. Fish. Res. 110:198-206. Article

Kotwicki, S., A. De Robertis, J. N. Ianelli, A. E. Punt, and J. K. Horne.

2013. Combining bottom trawl and acoustic data to model acoustic dead zone correction and bottom trawl efficiency parameters for semipelagic species. Can. J. Fish. Aquat. Sci. 70:208-219. Article

Kotwicki, S., J. N. Ianelli, and A. E. Punt.

2014. Correcting density-dependent effects in abundance estimates from bottom-trawl surveys. ICES J. Mar. Sci. 71:1107-1116. Article

Lauth, R. R., and D. G. Nichol.

2013. Results of the 2012 eastern Bering Sea continental shelf bottom trawl survey of groundfish and invertebrate resources. NOAA Tech. Memo. NMFS-AFSC-256, 162 p.

MacLennan, D. N., P. G. Fernandes, and J. Dalen.

2002. A consistent approach to definitions and symbols in fisheries acoustics. ICES J. Mar. Sci. 59:365-369. Article

Main, J., and G. I. Sangster.

1981. A study of the fish capture process in a bottom trawl by direct observations from a towed underwater vehicle. Scott. Fish. Res. Rep. No. 23, 23 p.

Maunder, M. N., and K. R. Piner.

2015. Contemporary fisheries stock assessment: many issues still remain. ICES J. Mar. Sci. 72:7-18. Article

Maunder, M. N., and A. E. Punt.

2013. A review of integrated analysis in fisheries stock assessment. Fish. Res. 142:61-74. Article

Maunder, M. N., P. R. Crone, J. L. Valero, and B. X. Semmens. 2014. Selectivity: theory, estimation, and application in fishery stock assessment models. Fish. Res. 158: 1-4. Article

Methot, R. D., Jr., and C. R. Wetzel.

2013. Stock synthesis: a biological and statistical framework for fish stock assessment and fishery management. Fish. Res. 142:86-99. Article

Nichol, D. G., T. Honkalehto, and G. G. Thompson.

2007. Proximity of Pacific cod to the seafloor: using archi- val tags to estimate fish availability to research bottom trawls. Fish. Res. 86:129-135. Article

Ona, E., and R. B. Mitson.

1996. Acoustic sampling and signal processing near the seabed: the deadzone revisited. ICES J. Mar. Sci. 53: 677-690. Article

Restrepo, V. R., J. Ortiz de Umbra, J.-M. Fromentin, and H. Arrizabalaga.

2007. Estimates of selectivity for eastern Atlantic bluefin tuna from catch curves. Collect. Vol. Sci. Pap. ICCAT. 60:937-948.

Somerton, D. A., and K. L. Weinberg.

2001. The affect of speed through the water on footrope contact of a survey trawl. Fish. Res. 53:17-24. Article

Somerton, D. A., P. T. Munro, and K. L. Weinberg.

2007. Whole-gear efficiency of a benthic survey trawl for flatfish. Fish. Bull. 105:278-291.

Somerton, D. A., K. L. Weinberg, and S. E. Goodman.

2013 Catchability of snow crab (Chionoecetes opilio) by the eastern Bering Sea bottom trawl survey estimated using a catch comparison experiment. Can. J. Fish. Aquat. Sci. 70:1699-1708. Article

Stauffer, G.

2004. NOAA protocols for groundfish bottom trawl surveys of the nation's fishery resources. NOAA Tech. Memo. NMFS-F/SPO-65, 205 p.

Thompson, G. G.

1994 Confounding of gear selectivity and the natural mortality rate in cases where the former is a nonmonotone function of age. Can. J. Fish. Aquat. Sci. 51:26542664 Article

Walsh, S. J.

1991. Diel variation in availability and vulnerability of fish to a survey trawl. J. Appl. Ichthyol. 7:147-159. Article

Weinberg, K. L.

2003. Change in the performance of a Bering Sea survey trawl due to varied trawl speed. Alaska Fish. Res. Bull. $10: 42-49$

Weinberg, K. L., D. A. Somerton, and P. T. Munro.

2002. The effect of trawl speed on the footrope capture efficiency of a survey trawl. Fish. Res. 58:303-313. Article

Weinberg, K. L., R. S. Otto, and D. A. Somerton.

2004. Capture probability of a survey trawl for red king crab (Paralithodes camtschaticus). Fish. Bull. 102: 740-749.

Wileman, D. A., R. S. T. Ferro, R. Fonteyne, and R. B. Millar (eds.).

1996. Manual of methods of measuring the selectivity of towed fishing gears. ICES Coop. Res. Rep. 215, 126 p.

Winger, P. D., P. He, and S. J. Walsh.

1999. Swimming endurance of American plaice (Hippoglossoides platessoides) and its role in fish capture. ICES J. Mar. Sci. 56:252-265. Article

2000. Factors affecting the swimming endurance and catchability of Atlantic cod (Gadus morhua). Can. J. Fish. Aquat. Sci. 57:1200-1207. Article 